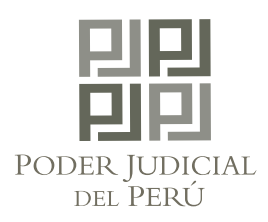

\title{
REUNIÓN ANUAL DE PRESIDENTES Y ADMINISTRADORES DE LAS CORTES SUPERIORES DE JUSTICIA 2013
}

\author{
Huaraz, 19 y 20 de abril de 2013
}

\section{DECLARACIÓN DE HUARAZ}

En la ciudad de Huaraz, a los 20 días del mes de abril de 2013, en las instalaciones del Centro Cultural de Huaraz, reunidos los integrantes del Consejo Ejecutivo del Poder Judicial y los presidentes de las 31 Cortes Superiores de Justicia del Perú, declaramos lo siguiente:

Primero: DESTACAR que el Consejo Ejecutivo del Poder Judicial respalda los planes y acciones que viene desarrollando el señor doctor Enrique Javier Mendoza Ramírez, en aras de consolidar la eficiencia en el servicio de justicia, mediante la adopción de diversas medidas administrativas tendentes a mejorar la infraestructura inmobiliaria, gestión del despacho, medición del desempeño y descarga procesal.

Segundo: RESPALDAR las decisiones de la Presidencia del Poder Judicial y del Consejo Ejecutivo, de declarar en emergencia la situación inmobiliaria de este Poder del Estado, cuya precariedad de los locales donde funcionan los órganos jurisdiccionales se da tanto en la capital de la República como en todas las cortes del país.

Tercero: APOYAR las decididas gestiones que viene realizando la Presidencia del Poder Judicial para lograr que el Poder Ejecutivo cumpla con satisfacer las justas reclamaciones remunerativas de los jueces y trabajadores, dentro del marco legal, así como de las sentencias dictadas por el Poder Judicial y el Tribunal Constitucional. 
Cuarto: ASUMIR el compromiso, por parte de los presidentes de las cortes superiores, a gestionar el apoyo de los gobiernos locales y regionales a nivel nacional, mediante la donación de terrenos o el financiamiento de las edificaciones de los locales judiciales, con el fin de lograr que se disminuya el alto número de inmuebles arrendados o en cesión de uso, para que pasen a ser propiedad del Poder Judicial. Por lo cual, exhortamos al Ministerio de Economía y Finanzas, a través de las gestiones que realice la Presidencia del Poder Judicial, que posibilite a los gobiernos regionales y locales el apoyo al Poder Judicial en materia inmobiliaria.

Quinto: UTILIZAR todos los medios informáticos disponibles y optimizar las herramientas informáticas en el corto plazo, maximizando el uso de las videoconferencias a fin de ahorrar tiempo, dinero y esfuerzo, tanto en la realización de actividades jurisdiccionales como administrativas.

Sexto: AUNAR esfuerzos para desarrollar y aplicar los estándares de producción y los diversos indicadores que emiten los órganos de gobierno del Poder Judicial, y toda medida que permita lograr los objetivos de descarga procesal.

Séptimo: DISPONER que los entes administrativos del Poder Judicial, fomenten espacios de coordinación técnica para la unificación de criterios estadísticos, a fin de contar con una sola base de datos a nivel nacional.

FINALMENTE, manifestamos nuestro firme rechazo a todo acto de corrupción y los atentados contra la ética que afectan la buena imagen de la institución y de la mayoría de los jueces y servidores judiciales, que con su trabajo eficiente y sacrificado dignifican la noble labor del servicio de justicia.

\section{CONSEJO EJECUTIVO DEL PODER JUDICIAL}

\section{PRESIDENTES DE LAS CORTES SUPERIORES DE JUSTICIA DEL PERÚ}




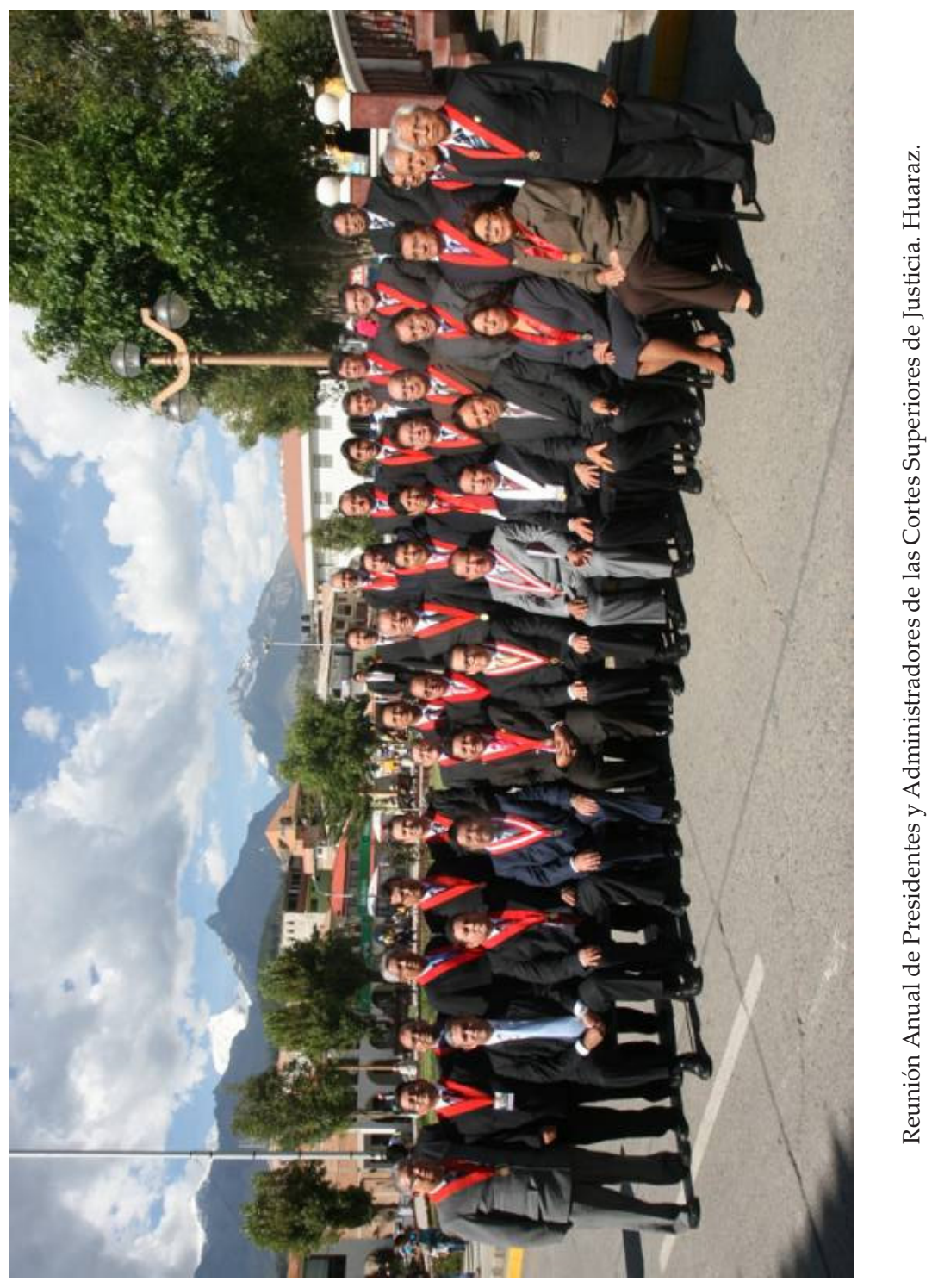

